\title{
Augmentation of Effective Thermal Gain of Solar Air Heater using a Novel Turbulator Design- A CFD Study
}

\author{
Animesh Dhagat ${ }^{1}$ and M. S. Manjunath ${ }^{2 *}$ \\ ${ }^{1}$ Department of Mechanical and Manufacturing Engineering, Manipal Institute of Technology, \\ Manipal Academy of Higher Education, Manipal-576104, India. \\ ${ }^{2}$ Department of Mechanical Engineering, School of Engineering and IT, Manipal University, Dubai, \\ $U A E$.
}

\begin{abstract}
Augmentation of thermal performance of solar air heater has been the focus of many researchers over the last decades and the use of turbulator or artificial roughness to provide increased fluid mixing in order to achieve augmented heat transfer has been a widely accepted technique. This work aims to evaluate the effect of a novel turbulator design on the effective thermal performance of solar air heater using the methodology of computational fluid dynamics (CFD). A two dimensional CFD analysis is carried out to evaluate the thermal characteristics of solar air heater at various flow Reynolds number conditions for different geometric parameters of the proposed turbulator design. The pitch of the turbulator is varied as $10 \mathrm{~mm}, 20 \mathrm{~mm}, 30 \mathrm{~mm}, 40 \mathrm{~mm}$ and $50 \mathrm{~mm}$ for a fixed turbulator height of $2 \mathrm{~mm}$. The Reynolds number is varied from 6,000 to 27,000. The analysis shows that the lower values of pitch produces higher improvement in heat transfer. The maximum increase in Nusselt number is found to be about 2.98 times as compared to the base model for the flow Reynolds number of about 6000 . The highest increase in the friction factor is found to be about 3.05 times relative to the base model. The maximum thermal enhancement factor is found to be about 1.99 for the pitch value of $10 \mathrm{~mm}$ at a flow Reynolds number of about 6000.
\end{abstract}

Keywords: Novel turbulator, Nusselt number, CFD, friction factor.

\section{Introduction}

One of the more abundantly available form of energy, solar energy is also difficult to harness. However, due to the current strain on petroleum and the almost depleted source of coal, there is now increasing research in order to harness this endless pool of energy. Solar Air Heater (SAH) is one such device that has been developed to achieve this very purpose. Though conceptually it's not very new, there is immense scope for improving the conventional device so as to derive the most at the least expense. A lot of research has been made in this particular field and many designs have been tested both experimentally and computationally. Bhagoria and Saini [1] conducted experiments on rectangular duct solar air heaters where they added

\footnotetext{
* Corresponding author: manjunathnitc@gmail.com
} 
roughness through wedge shaped turbulators having fixed values of relative roughness height and wedge angle. They found that varying the pitch of the roughness affected the heat transfer. They concluded that as the Reynolds numbe0mnr increases, the Nusselt number correspondingly increases while the friction factor subsequently decreases. Another study by Gawande et al. [2] investigating the heat transfer in solar air heater with reverse L-shaped ribs concluded that the average Nusselt number increases with increasing Reynolds number and also that the average Nusselt number increases with decreasing roughness pitch $(\mathrm{P} / \mathrm{e})$ for constant height of the roughness (e/D). Certain other studies have pointed towards using corrugated absorber plates. Handoyo et al. [3] studied the effect of delta shaped obstacles in a V-corrugated channel of a SAH. They concluded that the backflow being caused in between the obstacles and the high velocity in the gap between the obstacles and the absorber plate make the flow more turbulent and in turn increase the convective heat transfer. Though this will be at the expense of pressure drop. Yadav and Bhagoria [4] used square sectioned rib roughened duct to induce turbulence in the SAH and found the best thermo-hydraulic performance at roughness pitch $(\mathrm{P} / \mathrm{e})$ of 10.71 and roughness height (e/D) of 0.042 . Sharma and Kalamkar [5], through their study on the effect of rib turbulators have concluded that the flow reattachment along with unsteady reverse flow taking place in front of the ribs increases the time averaged heat transfer in turbulent flow. They have also found that SST k-w and RNG k-epsilon turbulence models are in good agreement with experimental results and that RNG k-epsilon turbulence model is the more widely used model in analysis involving artificial roughness in the solar air heaters. Further, Yadav and Bhagoria [6] also established that the RNG k-epsilon model yields the best results for two dimensional flows in a conventional air heater. Nowzari et al. [7] tested single pass and double pass air heaters and found that the efficiency of the double pass solar air heater was always greater than the single pass air heater by $5-22.7 \%$ for the same air mass flow rate. Alam and Kim [8] investigated the effect of semi elliptic turbulators placed in two arrangements: inline and staggered. For each arrangement, they varied the angle of attack $(\alpha)$ between $30^{\circ}$ to $90^{\circ}$. From the results, they found that for the angle of attack of $75^{\circ}$, the staggered arrangement yielded a Nusselt number enhancement of 2.05 while the corresponding enhancement in the case of inlet arrangement was 1.73 . They were thus able to conclude that turbulence and the lateral movement of air at an angle of attack of $75^{\circ}$ were responsible for the increase in the Nusselt number for both arrangements of turbulators.

Thus, the various works reported in the literature on the use of turbulators reveal the fact that the performance of solar air heater varies with varying turbulator configurations which has led to the development of different designs of turbulator in the quest for achieving increased levels of thermal performance. This work aims to evaluate the effect of a novel turbulator design on the effective thermal performance of solar air heater using the methodology of computational fluid dynamics (CFD). A two dimensional CFD analysis is carried out to evaluate the thermal characteristics of solar air heater at various flow Reynolds number conditions for different geometric parameters of the proposed turbulator design.

\section{Computational Domain, Boundary Conditions and Material Properties}

The air heater has been divided into three sections namely: inlet, test and outlet section as shown in Fig. 1(a) [9]. The absorber plate of thickness $1.0 \mathrm{~mm}$ has been placed at the top of the test section (Fig. 1(a)). The test section has a length of $500 \mathrm{~mm}$ and the inlet and outlet have equal length of $245 \mathrm{~mm}$. The height of the inlet, test section and outlet is fixed at 20 $\mathrm{mm}$ as shown in Fig. 1(a). The turbulators have been fixed below the absorber plate in the test section as shown in Fig. 1(b). The various configurations of turbulator considered in the 
analysis are listed in Table 1 while the thermo-physical properties of air are listed in Table 2. Meshing of a portion of the computational domain is shown in Fig. 2.

Table 1. Various turbulator configurations

Table 2. Thermo-physical properties of air

\begin{tabular}{|c|c|c|}
\hline $\begin{array}{c}\text { Rib } \\
\text { height } \\
(\mathrm{mm})\end{array}$ & Pitch $(\mathrm{mm})$ & $\begin{array}{l}\text { Hydraulic } \\
\text { diameter } \\
(\mathrm{mm})\end{array}$ \\
\hline \multirow{3}{*}{2.0} & 10 & \multirow{3}{*}{3} \\
\cline { 2 - 2 } & 20 & \multirow{2}{*}{33.33} \\
\cline { 2 - 2 } & 30 & \\
\cline { 2 - 2 } & 40 & \\
\hline
\end{tabular}

\begin{tabular}{|l|l|}
\hline Properties & Value \\
\hline Viscosity $\left(\mathrm{Nsm}^{-2}\right)$ & $1.85 \mathrm{e}-5$ \\
\hline Density $\left(\mathrm{kgm}^{-3}\right)$ & 1.18 \\
\hline Thermal conductivity $(\mathrm{W} / \mathrm{mK})$ & 0.02624 \\
\hline Specific heat $(\mathrm{kJ} / \mathrm{kgK})$ & 1006.43 \\
\hline
\end{tabular}

Absorber plate

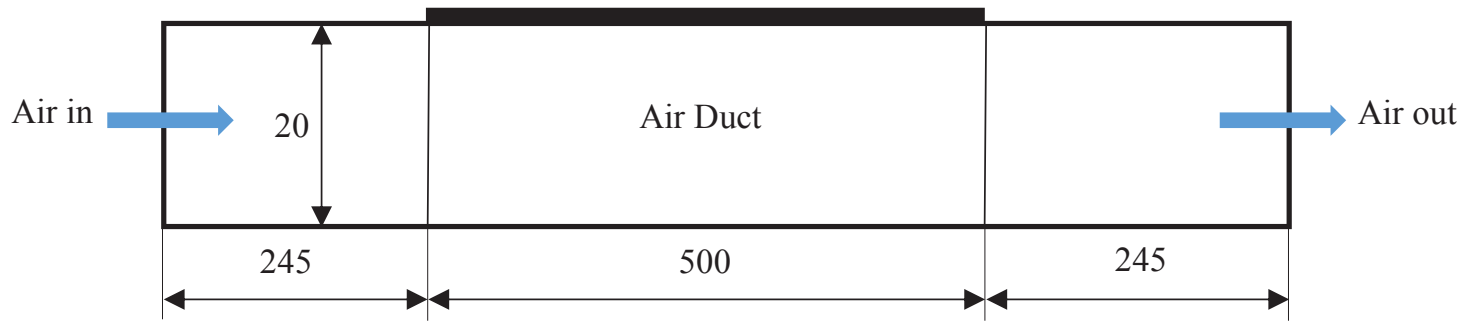

Fig. 1(a). Geometric details of solar air heater with plain absorber plate [9]. (All dimensions are in $\mathrm{mm})$

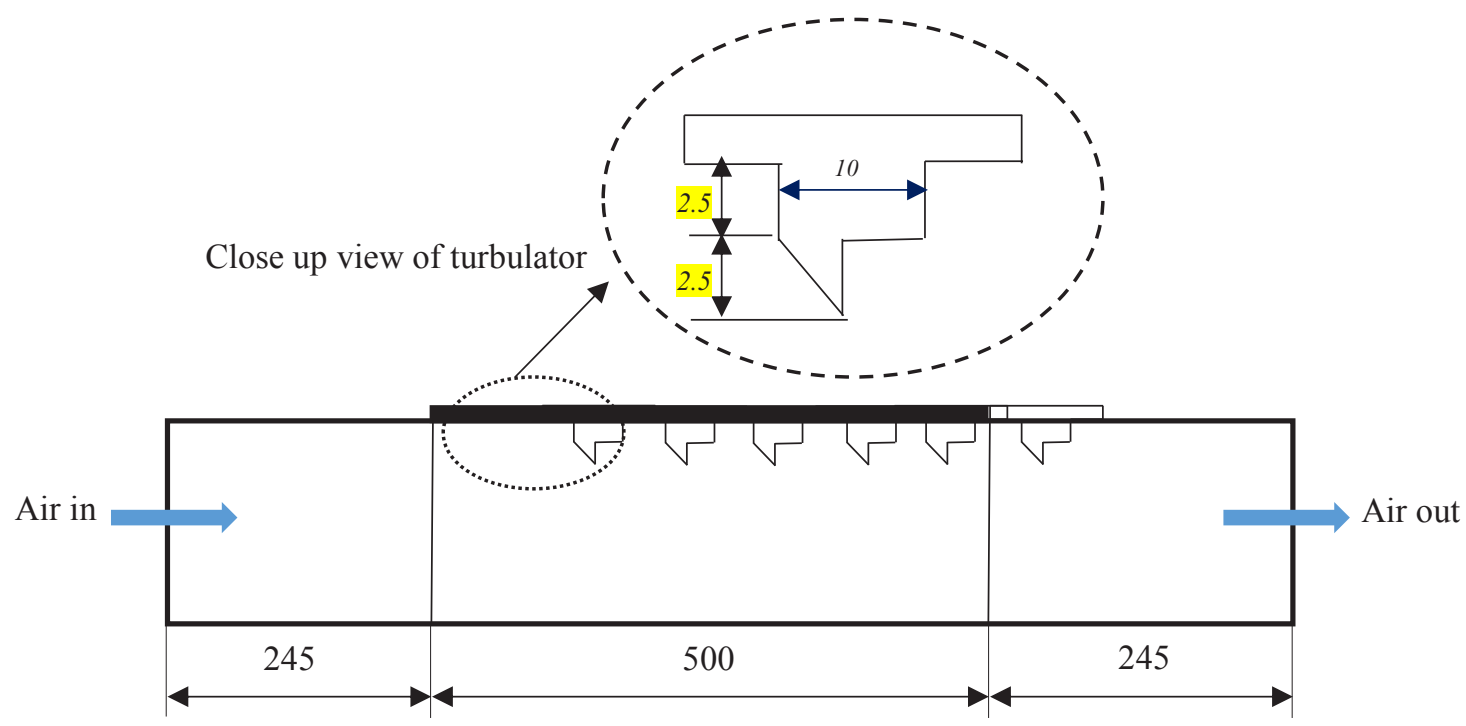

Fig. 1(b). Geometric details of solar air heater with turbulators on the absorber plate (All dimensions are in $\mathrm{mm}$ ) 
A constant heat flux of $1000 \mathrm{~W} / \mathrm{m}^{2}$ has been applied at the top surface of the absorber plate. The inlet of the duct has been set to 'mass-flow inlet' condition, and the variation of mass flow rate is between $0.07 \mathrm{~kg} / \mathrm{s}$ to $0.23 \mathrm{~kg} / \mathrm{s}$ which corresponds to the flow Reynolds number range of 6000-24000. The exit of the duct has been set to 'pressure outlet' condition with atmospheric pressure of $101323 \mathrm{~Pa}$. No-slip and impermeable condition is applied at the solid-fluid interface. All other boundaries are set as adiabatic wall. The flow is assumed to be steady and fully developed.

The discretization of the governing equation is carried out using the second order upwind scheme and the convergence of solution is considered when the residuals at the control volumes of the computational domain fell below 10-6 for all the flow parameters. The RNG $\mathrm{k}-\varepsilon$ turbulence model is used in the analysis [9] to capture the turbulent characteristics of flow.

Based on the grid independence test carried out by the authors on the base model in their previous study [9], a minimum of 0.221 million control volumes are maintained in the computational domain. The authors also carried out a validation study for the numerical solution of the base model in their previous study [9] and found that the numerical solution has good agreement with the Dittus-Boelter correlation for Nusselt number and Blassius solution for friction factor. The deviation of Nusselt number was found to be about $4.5 \%$ and for friction factor about $2.1 \%$

\section{Results and Discussions}

Fig. 3 shows the variation of Nusselt number for different flow rate conditions. It is observed that the Nusselt number for heat transfer from the absorber plate to air is generally higher relative to the plain duct. This is due to increased turbulence in the air flow in the presence of turbulators which is clear from Fig. 4 which shows the flow disturbances generated by the turbulator.

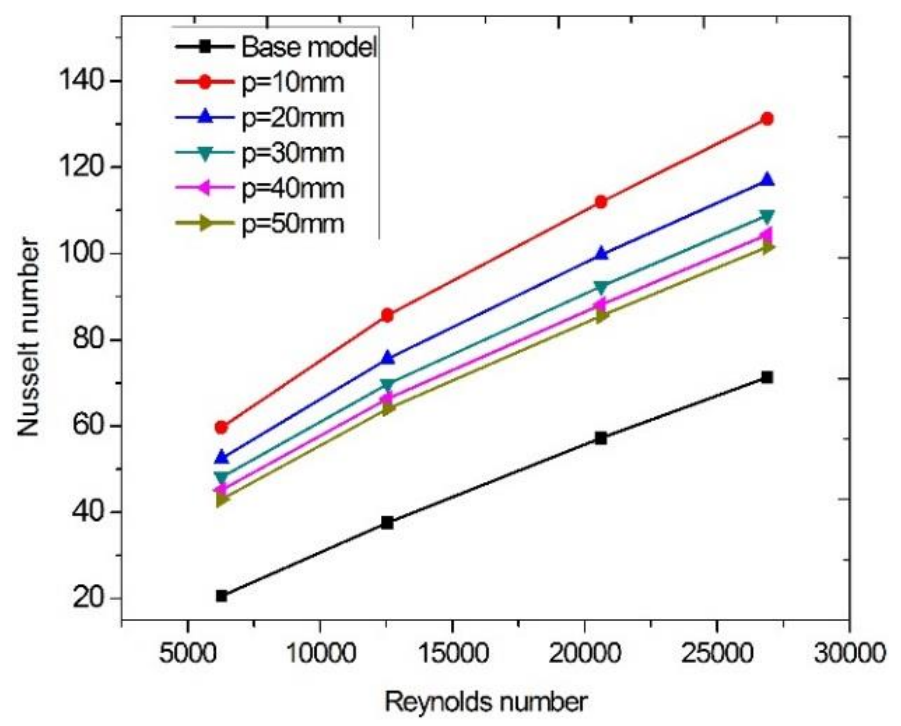

Fig. 3. Velocity vector plot of air flow around the turbulator. 


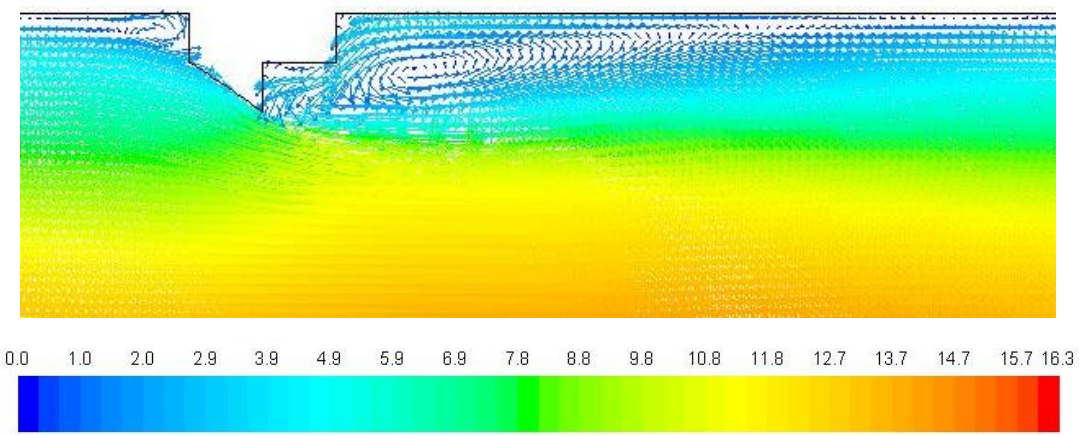

Fig. 4. Velocity vector plot of air flow around the turbulator.
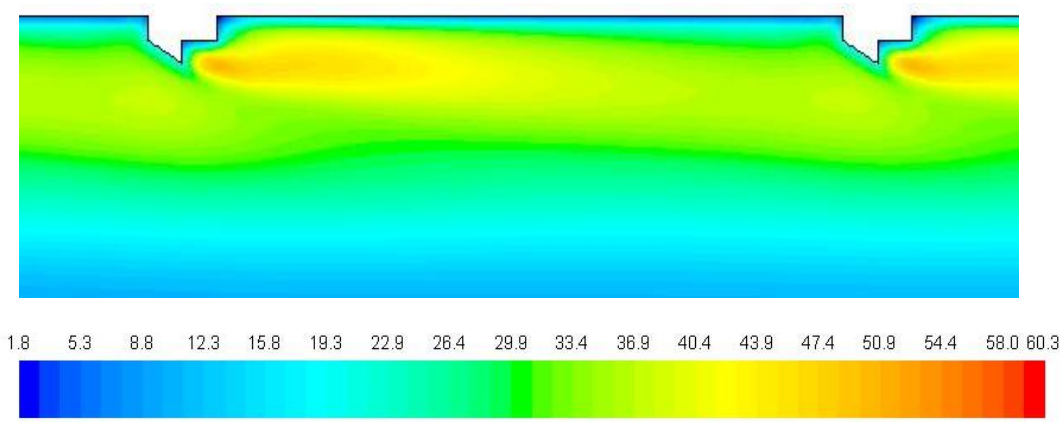

Fig. 5. Distribution of turbulent intensity (\%) around the turbulator. 


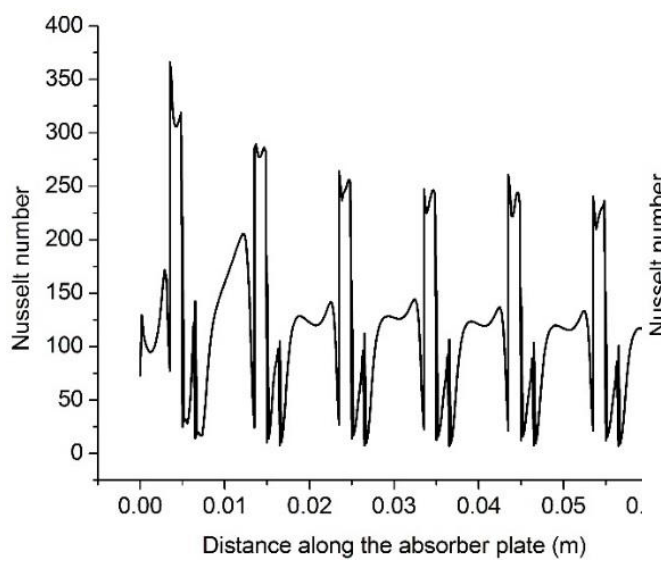

(a) $\mathrm{p}=10 \mathrm{~mm}$

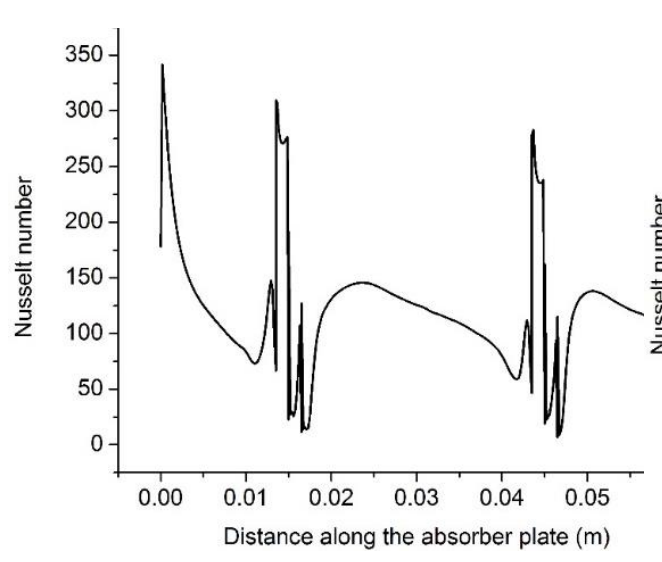

(c) $p=30 \mathrm{~mm}$

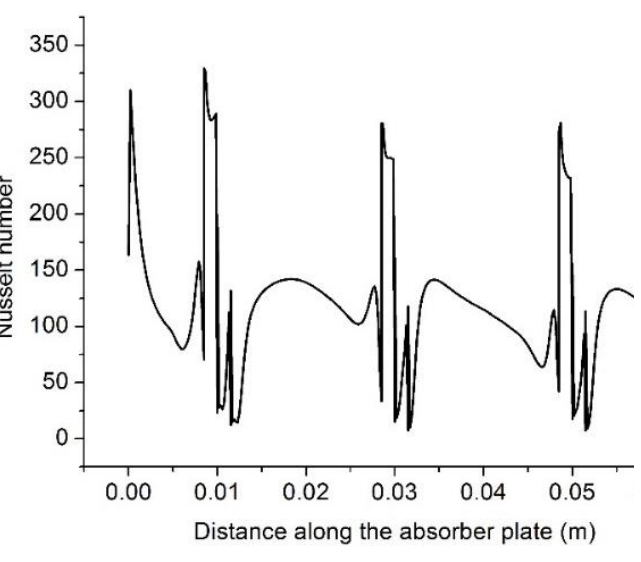

(b) $\mathrm{p}=20 \mathrm{~mm}$

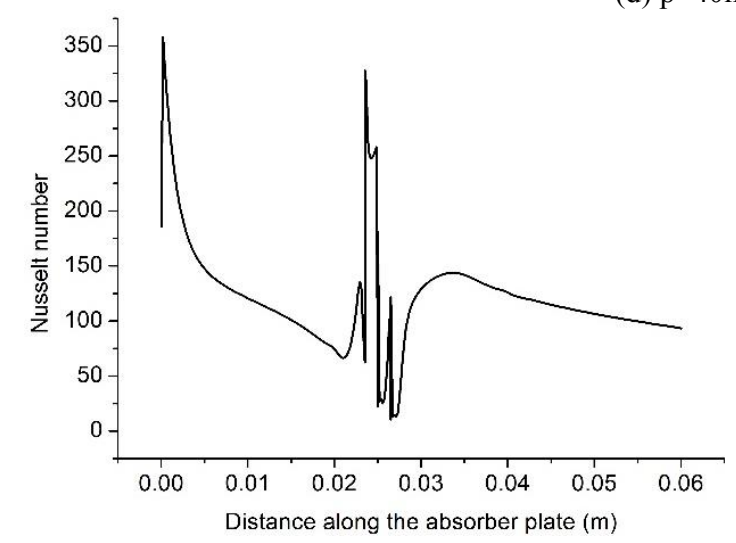

(e) $p=50 \mathrm{~mm}$

Fig. 6. Variation of Nusselt number along the length of absorber plate 
As the incoming air enters the test section, it impinges on the turbulator near the absorber plate. The shape of the turbulator is such that some portion of the air impinges on its vertical edge while some other portion hits the inclined edge and slides downward, as shown in Fig.4. This causes flow separation at the tip of the inclined leading edge of the turbulator surface and destroys the laminar sub-layer. The separated flow tends to reattach with the absorber surface on the downstream side of the turbulator and results in the formation of recirculation zones on the immediate downstream side of the turbulator. The flow recirculation zones interact with the separated flow and provide increased fluid mixing thereby providing higher energy transfer. The recirculation zones also ensure that the relatively colder air of the main flow stream is transported closer to the absorber surface thereby increasing the heat transfer. Fig. 5 shows the distribution of turbulent intensity in the air flow around the turbulator. It can be seen that the turbulent intensity is higher around the turbulator region thereby validating the fact that the presence of turbulator enhances fluid mixing and hence heat transfer.

Fig. 3 also shows that the Nusselt number increases with reducing pitch values at all flow rates of air. This is due to an increase in the total number of turbulators present in the test section at lower pitch values which produces turbulence in the air flow at a relatively larger number of locations leading to enhanced heat energy transfer. As the pitch increases, the number of turbulators gradually reduce and the number of regions at which the peak turbulence levels exist due to the presence of turbulators decreases thereby reducing the overall fluid mixing and hence energy transfer. Fig.6 shows the variation of Nusselt number along the length of absorber plate for different pitch values of the turbulator. It is clearly seen that the flow disturbances are at its peak around the turbulator region as indicated by a relatively higher values of Nusselt number at locations where the turbulators are attached to the absorber plate. For the pitch value of $10 \mathrm{~mm}$, the number of turbulators are large which results in a relatively larger instances of peak values of Nusselt number as shown in Fig. 6(a). As the pitch value increases, the number of instances of peak values of Nusselt number decreases owing to the reduction in the number of turbulators on the absorber plate as shown in Fig. 6(b) to Fig.6(e). Fig.6 also reveals that the highest value of Nusselt number occurs at the leading inclined edge of the turbulator. The reattachment points that exist on the absorber plate in the regions between the turbulators also exhibit peak values of Nusselt number thereby indicating enhanced heat transfer. The maximum increase in Nusselt number is found to be about 2.98 times as compared to the base model for the flow Reynolds number of about 6000. Fig. 7 shows the relative variation of friction factor in the presence of turbulator for different pitch values. It is seen that the friction factor is relatively higher in the presence of turbulator owing to an increased obstruction to the air flow which causes greater pressure loss across the duct. The highest increase in the friction factor is found to be about 3.05 times relatives to the base model. 


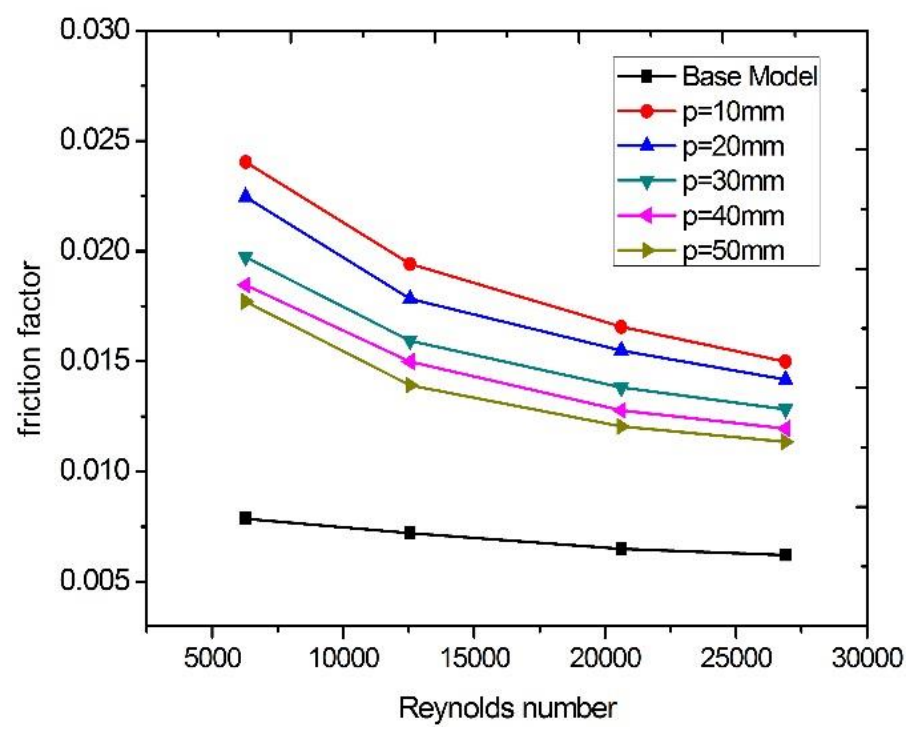

Fig. 7. Velocity vector plot of air flow around the turbulator.

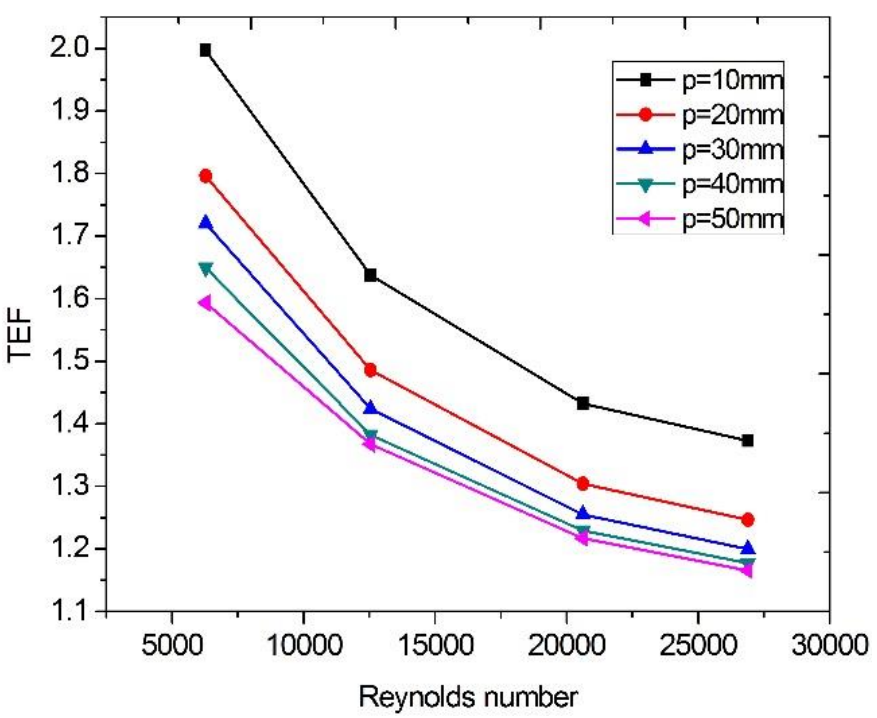

Fig. 8. Comparison of thermal enhancement factor for different pitch values of turbulator.

Fig. 8 shows the variation of thermal enhancement factor (TEF) which is calculated by eq.(1). The thermal enhancement factor indicates the effective thermal gain of a solar air heater by considering the relative increase of both the heat transfer and friction factor.

$$
T E F=\frac{\left(\frac{N u_{r}}{N u_{s}}\right)}{\left(\frac{f_{r}}{f_{s}}\right)^{1 / 3}}
$$


It can be seen that the TEF is higher than 1.0 in the presence of turbulator for all the flow rates and pitch values considered in the analysis. The effective thermal gain is found to be higher for lower pitch values of the turbulator for all the flow rate conditions. This is due to the fact that, at lower flow rates the heat transfer enhancement is found to be significantly higher as compared to higher pitch values. The maximum enhancement in thermal enhancement factor is found to be about 1.99 for the pitch value of $10 \mathrm{~mm}$ at a flow Reynolds number of about 6000 .

\section{Conclusions}

The following conclusions can be drawn from the analysis:

Lower values of pitch produces higher improvement in heat transfer. The maximum increase in Nusselt number is found to be about 2.98 times as compared to the base model for the flow Reynolds number of about 6000 .

- The highest increase in the friction factor is found to be about 3.05 times relatives to the base model.

- The maximum enhancement in thermal enhancement factor is found to be about 1.99 for the pitch value of $10 \mathrm{~mm}$ at a flow Reynolds number of about 6000 .

\section{Acknowledgement}

The computational facilities were provided by the Department of Mechanical and Manufacturing Engineering, Manipal Institute of Technology, Manipal, India which is thankfully acknowledged. This work is not part of any research grant.

\section{References}

1. J.L Bhagoria, J.S Saini, S.C Solanki, "Heat transfer coefficient and friction factor correlations for rectangular solar air heater duct having transverse wedge shaped rib roughness on the absorber plate", Renewable Energy, Volume 25, Issue 3, March 2002, Pages 341-369, ISSN 0960-1481, http://dx.doi.org/10.1016/S0960-1481(01)00057-X.

2. Vipin B. Gawande, A.S. Dhoble, D.B. Zodpe, Sunil Chamoli, "Experimental and CFD investigation of convection heat transfer in solar air heater with reverse L-shaped ribs", Solar Energy, Volume 131, June 2016, Pages 275-295, ISSN 0038-092X, http://dx.doi.org/10.1016/j.solener.2016.02.040.

3. Ekadewi A. Handoyo, Djatmiko Ichsani, Prabowo, Sutardi, "Numerical studies on the effect of delta-shaped obstacles' spacing on the heat transfer and pressure drop in vcorrugated channel of solar air heater", Solar Energy, Volume 131, June 2016, Pages 47 60, ISSN 0038-092X, http://dx.doi.org/10.1016/j.solener.2016.02.031.

4. Anil Singh Yadav, J.L. Bhagoria, "A numerical investigation of square sectioned transverse rib roughened solar air heater", International Journal of Thermal Sciences, Volume 79, May 2014, Pages 111-131, ISSN 1290-0729, http://dx.doi.org/10.1016/j.ijthermalsci.2014.01.008.

5. Sanjay K. Sharma, Vilas R. Kalamkar, "Computational Fluid Dynamics approach in thermo-hydraulic analysis of flow in ducts with rib roughened walls - A review", Renewable and Sustainable Energy Reviews, Volume 55, March 2016, Pages 756-788, ISSN 1364-0321, http://dx.doi.org/10.1016/j.rser.2015.10.160. 
6. Anil Singh Yadav, J.L. Bhagoria, "Heat transfer and fluid flow analysis of solar air heater: A review of CFD approach", Renewable and Sustainable Energy Reviews, Volume 23, July 2013, Pages 60-79, ISSN 1364-0321, http://dx.doi.org/10.1016/j.rser.2013.02.035.

7. Raheleh Nowzari, L.B.Y. Aldabbagh, F. Egelioglu, "Single and double pass solar air heaters with partially perforated cover and packed mesh", Energy, Volume 73, 14 August 2014, Pages 694-702, ISSN 0360-5442, http://dx.doi.org/10.1016/j.energy.2014.06.069.

8. Tabish Alam, Man-Hoe Kim, "Numerical study on thermal hydraulic performance improvement in solar air heater duct with semi ellipse shaped obstacles", Energy, Volume 112, 1 October 2016, Pages 588-598, ISSN 0360-5442, http://dx.doi.org/10.1016/j.energy.2016.06.105.

9. M.S. Manjunath, K. Vasudeva Karanth, N.Yagnesh Sharma, "Numerical Analysis on the Influence of a Novel Semi-D shaped Turbulator on Heat Transfer Enhancement of Solar Air Heater", Proceedings of 2017 International Conference on Electronics, Computer \& Manufacturing Engineering, Singapore, March 29-30, 2017

10. ANSYS FLUENT 17.1, Documentation, ANSYS Inc, 2016. 